\title{
Pharmacokinetic Concentration Test
}

National Cancer Institute

\section{Source}

National Cancer Institute. Pharmacokinetic Concentration Test. NCI Thesaurus. Code C87972.

A character or string that represents a pharmacokinetic concentration examination. 